\title{
Lipid management in the prevention of stroke: a meta-analysis of fibrates for stroke prevention
}

\author{
Yu-Hao Zhou ${ }^{\dagger}$, Xiao-Fei Ye ${ }^{\dagger}$, Fei-Fei Yu, Xiao Zhang, Ying-Yi Qin, Jian Lu and Jia He
}

\begin{abstract}
Background: Fibrates has been extensively used to improve plasma lipid levels and prevent adverse cardiovascular outcomes. However, the effect of fibrates on stroke is unclear at the present time. We therefore carried out a comprehensive systematic review and meta-analysis to evaluate the effects of fibrates on stroke.

Methods: We systematically searched Medline, Embase, the Cochrane Central Register of Controlled Trials, reference lists of articles, and proceedings of major meetings to identify studies for our analysis. We included randomized placebo controlled trials which reported the effects of fibrates on stroke. Relative risk (RR) was used to measure the effect of fibrates on the risk of stroke under random effect model. The analysis was further stratified by factors that could affect the treatment effects.
\end{abstract}

Results: Overall, fibrate therapy was not associated with a significant reduction on the risk of stroke (RR, 1.02, $95 \% \mathrm{Cl}, 0.90$ to $1.16, \mathrm{P}=0.78$ ). In the subgroup analyses, we observed that gemfibrozil therapy showed a beneficial effect on stroke $(R R, 0.72,95 \% \mathrm{Cl}, 0.53$ to $0.98, \mathrm{P}=0.04)$. Similarly, fibrate therapy comparing to placebo had no effect on the incidence of fatal stroke. Subgroup analysis suggested that fibrate therapy showed an effect on fatal stroke when the Jadad score more than 3 ( $R R, 0.41,95 \% \mathrm{Cl}, 0.17$ to $1.00, \mathrm{P}=0.049$ ). Furthermore, a sensitivity analysis indicated that fibrate therapy may play a role in fatal stroke (RR, $0.49,95 \% \mathrm{Cl}, 0.26$ to $0.93, \mathrm{P}=0.03$ ) for patients with previous diabetes, cardiovascular disease or stroke.

Conclusions: Our study indicated that fibrate therapy might play an important role in reducing the risk of fatal stroke in patients with previous diabetes, cardiovascular disease or stroke. However, it did not have an effect on the incidence of stroke.

Keywords: Fibrates, Stroke, Meta-analysis

\section{Background}

Cardiovascular disease is the leading cause of premature morbidity and mortality for both men and women worldwide, accounting for $30.9 \%$ of global mortality and $10.3 \%$ of global burden of disease [1,2]. Over the past few decades, a series of studies have shown a strong correlation between hypertriglyceridemia and cardiovascular disease. Those studies indicated that elevated triglyceride levels as a risk factor of coronary artery disease. In addition, it has been suggested that raised triglycerides in the blood should be lowered as a therapeutic approach to prevent cardiovascular disease [3-7]. However, reduction of the

\footnotetext{
* Correspondence: hejia63@yahoo.com

${ }^{\dagger}$ Equal contributors

Department of Health Statistics, Second Military Medical University, Shanghai 200433, China
}

concentrations of triglycerides in the blood has not been shown consistently to be beneficial for stroke [8].

Recently, a meta-analysis [5] revealed that statins could effectively achieve target cholesterol goals and reduce the risk of stroke. However, certain patients intolerant to statins also need stroke prevention. In addition, a high residual risk of coronary and other cardiovascular events persists during the statin therapy. It is necessary to find additional effective preventive therapies. Fibrates has been clearly shown to be effective in elevating HDL cholesterol, lowering triglyceride concentrations, reducing LDL cholesterol and chylomicron remnants [9]. However, inconsistent clinical results have been reported $[8,10]$, and the efficacy of fibrates lowering triglyceride levels in reducing the risk of stroke has not been confirmed by randomized trials.

\section{Biomed Central}


Although a number of trials indicated that fibrates had limited effect on the event of stroke. VA-HIT study [10] showed that fibrates significantly reduced the risk of stroke. In order to reveal the effect of fibrates on the event of stroke further, data from recent trials is needed to be re-evaluated and combined with former literatures. Therefore, we carried out a systematic review and metaanalysis of pooled data from randomized controlled trials which reported stroke as the endpoint in relation to fibrate therapy.

\section{Methods}

\section{Data sources, search strategy, and selection criteria}

Randomized, double-blind, placebo-controlled, and trials of fibrate therapy in English-language literature were eligible for inclusion in our research, regardless of publication status (published, unpublished, in press, or in progress). References of our meta-analysis were identified through searches of Pubmed, EmBase, and the Cochrane Central Register of Controlled Trials, with a date up to Dec 10, 2011. We searched with the following terms "clofibrate", "bezafibrate", "gemfibrozil", "fenofibrate", "procetofen", and "randomised controlled trials". The search was restricted to trials in human beings and published in English. References were also identified by screening the proceedings of annual meeting, bibliographies of publications for potentially relevant trials. We restricted our research to randomized controlled trials, which were less likely to be subject to confounding and bias than observational studies. Studies were eligible for inclusion when they met the following requirements: randomized controlled design; the intervention duration was at least 6 months and follow-up period was more than 12 months; recorded data on the event of stroke. The literature search was undertaken independently by 2 authors (Fei-Fei Yu and Ying-Yi. Qin) with a standardized approach, and any disagreement between these 2 authors was settled by a third author (Yu-Hao. Zhou) until a consensus was reached. This review was conducted and reported according to the PRISMA (Preferred Reporting Items for Systematic Reviews and Meta-Analysis) Statement issued in 2009 (Additional file 1) [11].

\section{Data collection and quality assessment}

3,279 identified studies were reviewed by 2 authors (Xiao-Fei Ye and Xiao Zhang) independently. Other two investigators (Ying-Yi Qin and Jian Lu) independently checked each full-text trial for eligibility and extracted and tabulated all relevant data with a standard protocol and reviewed by a third investigators (Yu-Hao Zhou). Any discrepancy was settled by group discussion, and then the primary authors (Yu-Hao. Zhou and Jia $\mathrm{He}$ ) made the final decision. Recorded data variables were shown as follows: first author or study group's name, publication year, the number of patients enrolled, gender, mean age, pre-existent diseases, percentage of diabetes, total cholesterol, blinding, interventions, control, the duration of follow-up, lifestyle modification, and the event of stroke. Study quality was assessed by the Jadad score [12].

\section{Statistical analysis}

We assessed the overall effect of fibrate therapy on the risk of stroke based on all data from the included trials. Outcome was reported by relative risks (RR) with 95\% confidence intervals (CIs) to evaluate the effect of fibrate therapy on the event of stroke. We then performed subgroup analysis by the type of drug (clofibrate, bezafibrate, gemfibrozil, or fenofibrate), mean age ( $\geq 60$ or $<60$ ), triglyceride lowering ( $\geq 10 \%$ or $<10 \%$ ), pre-exsistent diseases (diabetes, stroke, or other), number of patients ( $\geq 1000$ or $<1000$ ), published years (after 2000 or previous), duration of follow-up ( $\geq 60$ months or $<60$ months), baseline total cholesterol $(\geq 6.0 \mathrm{mmol} / \mathrm{L}$ or $<6.0 \mathrm{mmol} / \mathrm{L})$, total cholesterol lowering ( $\geq 5 \%$ or $<5 \%)$, triglyceridemia $(\geq 30 \%$ or $<30 \%$ ), or Jadad score (score 4 or 5 , less than 4 ). Furthermore, the effect of between-group triglyceride lowering, and total cholesterol change on stroke incidence was assessed by linear regression model for the logarithmic relative risk of stroke. Although the fixed-effect and random-effect models yielded similar conclusions, we used random-effect model with Mantel-Haenszel statistics in our study. Under this model, we assumed that the true underlying effect varied among included trials due to the different pre-existent diseases, intervention regimens, and the duration of follow-up which were involved in the original trials. Moreover, many investigators also considered the random-effect model to be a more natural choice than the fixed-effect model in medical decision-making contexts $[13,14]$. Heterogeneity of treatment effects among studies was investigated by scatter plot analysis and the heterogeneity $\mathrm{I}^{2}$ statistic [15]. Egger's test [16] was used to check for potential publication bias. All $\mathrm{P}$ values were reported as two-sided and $\mathrm{P}$ values less than 0.05 were regarded as statistically significant for all included studies. SAS software (version 9.1.3) was used for the regression analysis and STATA (version 10.0) was used for the metaanalysis.

\section{Results}

We identified 3,279 potential trials from our initial searches and 3,191 were excluded during a preliminary review. Among the 88 trials retrieved for detailed assessment, 78 trials were excluded for lack of data on stroke, polytherapy in either treatment group or control group, or reporting the same population. Our final analysis included 10 randomized controlled trials, which consisted of 37,791 individual patients. Table 1 summarized 
Table 1 Baseline characteristic of trials participants

\begin{tabular}{|c|c|c|c|c|c|c|}
\hline Source & $\begin{array}{l}\text { No. of } \\
\text { patients }\end{array}$ & Gender (male) & $\begin{array}{l}\text { Mean } \\
\text { age, y }\end{array}$ & Pre-existent diseases & Diabetes & $\begin{array}{c}\begin{array}{c}\text { Total } \\
\text { cholesterol } \\
(\mathrm{mmol} / \mathrm{L})\end{array} \\
\end{array}$ \\
\hline BIP study [8] (2000) & 3090 & $2825(91 \%)$ & 60 & $\begin{array}{c}\text { MI more than } 6 \text { month, and less than } \\
5 \text { year and/or stable angina }\end{array}$ & $10 \%$ & 5.5 \\
\hline VA-HIT study [10] (1999) & 2531 & $2531(100 \%)$ & 64 & Histories of CHD & $25 \%$ & 4.5 \\
\hline Acheson J [17] (1972) & 95 & $65(68 \%)$ & NR & Cerebral vascular disease & $\begin{array}{l}\text { Excluded severe } \\
\text { diabetics }\end{array}$ & 7.5 \\
\hline $\begin{array}{l}\text { Veterans Administration Cooperative } \\
\text { Study Group [18] (1973) }\end{array}$ & 532 & $532(100 \%)$ & NR & cerebral I or TIA within 12 month & $24 \%$ & 6.2 \\
\hline $\begin{array}{l}\text { Coronary Drug Project Research Group } \\
\text { [19] (1975) }\end{array}$ & 3892 & $3892(100 \%)$ & NR & Ml more than 3 month & NR & 6.5 \\
\hline $\begin{array}{l}\text { WHO-COOP committee of principal } \\
\text { Investigators [20] (1978) }\end{array}$ & 10627 & $10627(100 \%)$ & 46 & $\begin{array}{l}\text { Upper third level of cholesterol from } \\
15745 \text { healthy men }\end{array}$ & $0 \%$ & 6.4 \\
\hline LEADER study $[21,22](2002)$ & 1568 & $1568(100 \%)$ & 68 & lower extremity arterial disease & $66 \%$ & 5.6 \\
\hline E J Whitney [23] (2005) & 9795 & $6138(63 \%)$ & 62 & Type 2 diabetes mellitus & $100 \%$ & 5.0 \\
\hline FIELD study [24] (2005) & 143 & $132(92 \%)$ & 63 & Low HDL-C and coronary disease & NR & 5.1 \\
\hline The ACCORD Study Group [25] (2010) & 5518 & $3824(69 \%)$ & 62 & Type 2 diabetes mellitus & $100 \%$ & 5.0 \\
\hline
\end{tabular}

the baseline characteristics of the included studies and their participants. Design characteristics of included trials were presented in Table 2. The trials compared fibrate therapy with placebo were included in our research. Sample size of the trials ranged from 95 to 10,627, with a mean of 3,779 , and the duration of follow-up for patients ranged from 30 to 104 months. 4 of included trials [17-20] evaluated the effect of clofibrates, 2 trials $[8,21,22]$ evaluated the effect of bezafibrate, 2 studies $[10,23]$ evaluated the effect of gemfibrozil, and the remaining 2 studies $[24,25]$ evaluated the effect of fenofibrate. In addition, 9 trials included patients with preexisting disease: 2 trials $[17,18]$ reported that patients had the history of cerebral or TIA, and the remaining 7 trials $[8,10,19,21-25]$ reported patients had the history of myocardial infarction, diabetes, coronary disease or lower extremity arterial disease. Another trial [20] included participants with high level of cholesterol. The quality of the trials was assessed according to the pre-fixed criteria using the Jadad score. Among the 10 included trials, five trials $[8,10,19,24,25]$ scored 4 , one [23] scored 3 , two [20,21] scored 2, one [18] scored 1 and the remaining one trial [17] scored 0.

After pooling included trials, we concluded that fibrate therapy had no effect on the risk of stroke (RR, 1.02; 95\% CI: 0.90 to 1.16). Heterogeneity test for all analysis in Table 3 showed that all $\mathrm{P}$ value for heterogeneity were larger than 0.05 , and heterogeneity was not statistically significant in the overall analysis and in subgroup analysis. Furthermore, sensitivity analysis also showed that

Table 2 Design of trials included in the systematic review and meta-analysis

\begin{tabular}{|c|c|c|c|c|c|c|}
\hline Source & Blinding & Intervention & Control & Follow-up (month) & $\begin{array}{c}\text { Lifestyle } \\
\text { intervention }\end{array}$ & $\begin{array}{l}\text { Jadad } \\
\text { score }\end{array}$ \\
\hline BIP study [8] (2000) & Double & Bezafibrate 400 mg daily & Placebo & 74.4 & Yes & 4 \\
\hline VA-HIT study [10] (1999) & Double & Gemfibrozil 1200 mg daily & Placebo & $36-60$ & Yes & 4 \\
\hline Acheson J [17] (1972) & Open & Clofibrate $1-2 \mathrm{~g}$ daily & Corn oil then placebo & $\begin{array}{l}104 \text { in treatment group } \\
91 \text { in placebo group }\end{array}$ & NR & 0 \\
\hline $\begin{array}{l}\text { Veterans Administration Cooperative } \\
\text { Study Group [18] (1973) }\end{array}$ & Double & Clofibrate $2 \mathrm{~g}$ daily & Placebo & 54 & NR & 1 \\
\hline $\begin{array}{l}\text { Coronary Drug Project Research } \\
\text { Group [19] (1975) }\end{array}$ & Double & Clofibrate $1.8 \mathrm{~g}$ daily & Placebo & 74.4 & NR & 4 \\
\hline $\begin{array}{l}\text { WHO-COOP committee of principal } \\
\text { Investigators [20] (1978) }\end{array}$ & Double & Clofibrate $1.6 \mathrm{~g}$ daily & Olive oil Placebo & 63.6 & Yes & 2 \\
\hline LEADER study [21,22] (2002) & Double & Bezafibrate 400 mg daily & Placebo & 55.2 & NR & 2 \\
\hline E J Whitney [23] (2005) & Double & Gemfibrozil 600 mg daily & Placebo & 30 & Yes & 3 \\
\hline FIELD study [24] (2005) & Double & Fenofibrate 200 mg daily & Placebo & 60 & Yes & 4 \\
\hline The ACCORD Study Group [25] (2010) & Double & Fenofibrate 160 mg daily & Placebo & 56.4 & Yes & 4 \\
\hline
\end{tabular}


Table 3 Subgroup analysis for the effect of fibrates therapy on stoke, and fatal stroke

\begin{tabular}{|c|c|c|c|c|c|c|c|}
\hline & \multirow[t]{2}{*}{ Group } & \multicolumn{2}{|c|}{ Stroke event/total patients } & \multirow[t]{2}{*}{ Relative risk (RR) } & \multirow[t]{2}{*}{$P$ value } & \multirow[t]{2}{*}{ Heterogeneity } & \multirow{2}{*}{$\begin{array}{c}P \text { value for } \\
\text { heterogeneity }\end{array}$} \\
\hline & & Fibrates & Placebo & & & & \\
\hline \multirow[t]{40}{*}{ stroke } & \multicolumn{7}{|l|}{ Published years } \\
\hline & after 2000 & $341 / 10062$ & $351 / 10052$ & 0.97 (0.84 to 1.13$)$ & 0.72 & $0 \%$ & 0.51 \\
\hline & before 2000 & 292/8013 & $471 / 9664$ & 1.06 (0.84 to 1.33$)$ & 0.63 & $52 \%$ & 0.08 \\
\hline & \multicolumn{7}{|c|}{ Number of patients } \\
\hline & $\geq 1000$ & $573 / 17689$ & 775/19332 & $0.99(0.87,1.12)$ & 0.85 & $23 \%$ & 0.26 \\
\hline & $<1000$ & $60 / 386$ & $47 / 384$ & $1.23(0.80,1.90)$ & 0.34 & $30 \%$ & 0.24 \\
\hline & \multicolumn{7}{|l|}{ Mean age } \\
\hline & $<60$ & $32 / 5331$ & $27 / 5296$ & 1.18 (0.71 to 1.96$)$ & 0.53 & - & - \\
\hline & $\geq 60$ & $405 / 11326$ & 439/11319 & 0.93 (0.80 to 1.08$)$ & 0.34 & $17 \%$ & 0.30 \\
\hline & \multicolumn{7}{|l|}{ Gender } \\
\hline & male & $329 / 8749$ & 498/10401 & 1.09 (0.86 to 1.38$)$ & 0.47 & $56 \%$ & 0.06 \\
\hline & Male/female & $304 / 9326$ & $324 / 9315$ & 0.95 (0.82 to 1.10$)$ & 0.48 & $0 \%$ & 0.77 \\
\hline & \multicolumn{7}{|l|}{ Drug } \\
\hline & clofibrate & $228 / 6749$ & $383 / 8397$ & 1.15 (0.98 to 1.34$)$ & 0.08 & $0 \%$ & 0.59 \\
\hline & bezafibrate & $132 / 2331$ & $126 / 2327$ & 1.05 (0.80 to 1.38$)$ & 0.37 & $21 \%$ & 0.26 \\
\hline & gemfibrozil & $64 / 1335$ & $90 / 1339$ & 0.72 (0.53 to 0.98$)$ & 0.04 & $0 \%$ & 0.41 \\
\hline & fenofibrate & 209/7660 & $223 / 7653$ & 0.94 (0.78 to 1.13$)$ & 0.49 & $0 \%$ & 0.49 \\
\hline & \multicolumn{7}{|l|}{ Control } \\
\hline & corn or olive oil & $55 / 5378$ & $49 / 5344$ & 1.11 (0.80 to 1.54$)$ & 0.53 & $0 \%$ & 0.76 \\
\hline & placebo & $572 / 12697$ & $761 / 14372$ & 1.02 (0.88 to 1.17$)$ & 0.83 & $32 \%$ & 0.17 \\
\hline & \multicolumn{7}{|l|}{ Follow-up } \\
\hline & $\geq 60$ months & $421 / 12924$ & $612 / 14575$ & 1.01 (0.90 to 1.14$)$ & 0.85 & $0 \%$ & 0.62 \\
\hline & $<60$ months & $212 / 5151$ & $210 / 5141$ & 1.05 (0.76 to 1.46$)$ & 0.75 & $59 \%$ & 0.05 \\
\hline & \multicolumn{7}{|c|}{ Total cholesterol } \\
\hline & $\geq 6.0 \mathrm{mmol} / \mathrm{L}$ & 228/6749 & $383 / 8397$ & 1.15 (0.98 to 1.34$)$ & 0.08 & $0 \%$ & 0.59 \\
\hline & $<6.0 \mathrm{mmol} / \mathrm{L}$ & $405 / 11326$ & 439/11319 & 0.93 (0.80 to 1.08$)$ & 0.34 & $17 \%$ & 0.30 \\
\hline & \multicolumn{7}{|c|}{ Total cholesterol lowering } \\
\hline & $\geq 5 \%$ & $409 / 12230$ & $586 / 13890$ & $1.04(0.92$ to 1.18$)$ & 0.49 & $0 \%$ & 0.51 \\
\hline & $<5 \%$ & $173 / 3080$ & $188 / 3073$ & 0.98 (0.67 to 1.45$)$ & 0.93 & $71 \%$ & 0.03 \\
\hline & \multicolumn{7}{|c|}{ Triglyceride lowering } \\
\hline & $\geq 30 \%$ & $101 / 1603$ & $113 / 1603$ & 0.96 (0.46 to 1.99$)$ & 0.92 & $74 \%$ & 0.02 \\
\hline & $<30 \%$ & $477 / 11094$ & $660 / 12769$ & $1.02(0.91$ to 1.15$)$ & 0.69 & $0 \%$ & 0.51 \\
\hline & \multicolumn{7}{|c|}{ Pre-exsistent diseases } \\
\hline & stroke & $60 / 315$ & $45 / 312$ & 1.28 (0.86 to 1.90$)$ & 0.23 & $35 \%$ & 0.22 \\
\hline & diabetes & 209/7660 & $223 / 7653$ & 0.94 (0.78 to 1.13$)$ & 0.49 & $0 \%$ & 0.49 \\
\hline & other & $364 / 10100$ & $554 / 11751$ & $1.00(0.83$ to 1.20$)$ & 0.99 & $36 \%$ & 0.16 \\
\hline & \multicolumn{7}{|l|}{ Jadad score } \\
\hline & 4 & $481 / 11575$ & $699 / 13251$ & 0.95 (0.82 to 1.09$)$ & 0.48 & $30 \%$ & 0.22 \\
\hline & $<4$ & $152 / 6500$ & $123 / 6465$ & 1.22 (0.98 to 1.52$)$ & 0.07 & $0 \%$ & 0.58 \\
\hline & Overall & $633 / 18075$ & $822 / 19716$ & 1.02 (0.90 to 1.16$)$ & 0.78 & $27 \%$ & 0.20 \\
\hline \multirow[t]{3}{*}{ Fatal stroke } & \multicolumn{7}{|l|}{ Published years } \\
\hline & after 2000 & $17 / 3548$ & $17 / 3538$ & 0.93 (0.33 to 2.60) & 0.89 & $51 \%$ & 0.15 \\
\hline & before 2000 & $24 / 6910$ & $35 / 6875$ & $0.70(0.41$ to 1.19$)$ & 0.18 & $0 \%$ & 0.47 \\
\hline
\end{tabular}


Table 3 Subgroup analysis for the effect of fibrates therapy on stoke, and fatal stroke (Continued)

\begin{tabular}{|c|c|c|c|c|c|c|}
\hline \multicolumn{7}{|c|}{ Number of patients } \\
\hline$\geq 1000$ & $34 / 10143$ & 40/10101 & 0.82 (0.45 to 1.48 ) & 0.51 & $32 \%$ & 0.22 \\
\hline$<1000$ & $7 / 315$ & $12 / 312$ & 0.59 (0.23 to 1.47$)$ & 0.26 & $0 \%$ & 0.59 \\
\hline \multicolumn{7}{|l|}{ Mean age } \\
\hline$<60$ & $14 / 5331$ & $14 / 5296$ & 0.99 (0.47 to 2.08 ) & 0.99 & - & - \\
\hline$\geq 60$ & $20 / 4812$ & $26 / 4805$ & 0.69 (0.27 to 1.75$)$ & 0.44 & $53 \%$ & 0.12 \\
\hline \multicolumn{7}{|l|}{ Gender } \\
\hline male & $35 / 7646$ & $39 / 7612$ & 0.89 (0.53 to 1.51$)$ & 0.67 & $19 \%$ & 0.30 \\
\hline Male/female & $6 / 2812$ & $13 / 2801$ & 0.46 (0.18 to 1.21$)$ & 0.12 & $0 \%$ & 0.85 \\
\hline \multicolumn{7}{|l|}{ Drug } \\
\hline clofibrate & $21 / 5646$ & $26 / 5608$ & 0.81 (0.45 to 1.44 ) & 0.47 & $0 \%$ & 0.59 \\
\hline bezafibrate & $13 / 783$ & 9/785 & 1.45 (0.62 to 3.37 ) & 0.39 & - & - \\
\hline gemfibrozil & $3 / 1264$ & $9 / 1267$ & 0.33 (0.09 to 1.23 ) & 0.10 & - & - \\
\hline fenofibrate & $4 / 2765$ & $8 / 2753$ & 0.50 (0.15 to 1.65$)$ & 0.25 & - & - \\
\hline \multicolumn{7}{|l|}{ Control } \\
\hline corn or olive oil & $16 / 5378$ & $19 / 5344$ & 0.85 (0.43 to 1.66$)$ & 0.63 & $0 \%$ & 0.32 \\
\hline placebo & $25 / 5151$ & $33 / 5141$ & 0.73 (0.38 to 1.40 ) & 0.34 & $30 \%$ & 0.23 \\
\hline \multicolumn{7}{|l|}{ Follow-up } \\
\hline$\geq 60$ months & $16 / 5378$ & $19 / 5344$ & 0.85 (0.43 to 1.66$)$ & 0.63 & $0 \%$ & 0.32 \\
\hline$<60$ months & $25 / 5080$ & $33 / 5069$ & 0.73 (0.38 to 1.40$)$ & 0.34 & $30 \%$ & 0.23 \\
\hline \multicolumn{7}{|l|}{ Total cholesterol } \\
\hline$\geq 6.0 \mathrm{mmol} / \mathrm{L}$ & $21 / 5646$ & $26 / 5608$ & 0.81 (0.45 to 1.44$)$ & 0.47 & $0 \%$ & 0.59 \\
\hline$<6.0 \mathrm{mmol} / \mathrm{L}$ & $20 / 4812$ & $26 / 4805$ & 0.69 (0.27 to 1.75$)$ & 0.44 & $53 \%$ & 0.12 \\
\hline \multicolumn{7}{|c|}{ Total cholesterol lowering } \\
\hline$\geq 5 \%$ & $29 / 6161$ & 28/6129 & 1.04 (0.62 to 1.76$)$ & 0.87 & $0 \%$ & 0.38 \\
\hline$<5 \%$ & $8 / 1532$ & 16/1531 & 0.51 (0.22 to 1.20$)$ & 0.12 & $0 \%$ & 0.40 \\
\hline \multicolumn{7}{|c|}{ Triglyceride lowering } \\
\hline$\geq 30 \%$ & $8 / 1532$ & 16/1531 & 0.51 (0.22 to 1.20$)$ & 0.12 & $0 \%$ & 0.40 \\
\hline$<30 \%$ & $17 / 3548$ & $17 / 3538$ & 0.93 (0.33 to 2.60$)$ & 0.89 & $51 \%$ & 0.15 \\
\hline \multicolumn{7}{|c|}{ Pre-exsistent diseases } \\
\hline stroke & $7 / 315$ & $12 / 312$ & 0.59 (0.23 to 1.47$)$ & 0.26 & $0 \%$ & 0.59 \\
\hline diabetes & $4 / 2765$ & $8 / 2753$ & 0.50 (0.15 to 1.65$)$ & 0.25 & - & - \\
\hline other & $30 / 7378$ & $32 / 7348$ & 0.91 (0.45 to 1.83 ) & 0.78 & $42 \%$ & 0.18 \\
\hline \multicolumn{7}{|l|}{ Jadad score } \\
\hline 4 & $7 / 4029$ & $17 / 4020$ & 0.41 (0.17 to 1.00 ) & 0.05 & $0 \%$ & 0.66 \\
\hline$<4$ & $34 / 6429$ & $35 / 6393$ & 0.97 (0.60 to 1.57 ) & 0.91 & $0 \%$ & 0.51 \\
\hline Overall & $41 / 10458$ & $52 / 10413$ & 0.79 (0.51 to 1.23$)$ & 0.30 & $6 \%$ & 0.38 \\
\hline
\end{tabular}

the results were not affected by sequential exclusion of any particular trial.

Six trials [10,17,18,20,23,25] included 20871 individuals and 93 total events of fatal stroke were recorded. There was no evidence to support that fibrate therapy protected against fatal stroke (RR, 0.79; 95\% CI, 0.51 to 1.23 , Table 3 ) with homogenity across included studies. Furthermore, we observed that the results were not affected by excluding of any specific trial from the pooled analysis.

Post-intervention total cholesterol lowering was measured in all included studies except one [23]. There was considerable variation in the net and relative reduction of total cholesterol concentration among the included trials, ranging from $3.0 \%$ to $19.6 \%$ (Table 4). We observed an inverse relation between total cholesterol lowering and 


\begin{tabular}{|c|c|c|c|c|}
\hline Source & $\begin{array}{c}\text { Triglyceride } \\
\text { lowering }\end{array}$ & $\begin{array}{l}\text { Total cholesterol } \\
\text { lowering }\end{array}$ & $\begin{array}{c}\text { Relative risk (RR) } \\
\text { and } 95 \% \mathrm{Cl} \text { for stroke }\end{array}$ & $\begin{array}{c}\text { Relative risk (RR) } \\
\text { and } 95 \% \mathrm{Cl} \text { for fatal stroke }\end{array}$ \\
\hline BIP study [8] (2000) & $11.0 \%$ & $3.0 \%$ & $0.93(0.68,1.27)$ & - \\
\hline VA-HIT study [10] (1999) & $31.0 \%$ & $4.0 \%$ & $0.73(0.53,1.00)$ & $0.33(0.09,1.23)$ \\
\hline Acheson J [17] (1972) & NR & $6.4 \%$ & $1.07(0.70,1.63)$ & $0.41(0.08,2.00)$ \\
\hline $\begin{array}{l}\text { Veterans Administration Cooperative } \\
\text { Study Group [18] (1973) }\end{array}$ & $33.2 \%$ & $3.7 \%$ & $1.58(0.97,2.59)$ & $0.70(0.23,2.19)$ \\
\hline $\begin{array}{l}\text { Coronary Drug Project Research Group } \\
\text { [19] (1975) }\end{array}$ & $22.3 \%$ & $6.5 \%$ & $1.11(0.92,1.34)$ & - \\
\hline $\begin{array}{l}\text { WHO-COOP committee of principal } \\
\text { Investigators [20] (1978) }\end{array}$ & NR & $9.0 \%$ & $1.18(0.71,1.96)$ & $0.99(0.47,2.08)$ \\
\hline LEADER study [21,22] (2002) & $23.4 \%$ & $8.1 \%$ & $1.23(0.85,1.77)$ & $1.45(0.62,3.37)$ \\
\hline E J Whitney [23] (2005) & $21.5 \%$ & $6.8 \%$ & $0.90(0.73,1.12)$ & - \\
\hline FIELD study [24] (2005) & $49.8 \%$ & $19.6 \%$ & $0.20(0.01,4.15)$ & - \\
\hline The ACCORD Study Group [25] (2010) & $15.6 \%$ & $N R$ & $1.06(0.72,1.56)$ & $0.50(0.15,1.65)$ \\
\hline
\end{tabular}

incidence of stroke $(\mathrm{r}=-0.68, \mathrm{p}=0.044)$. When we stratified the trials by the degree of total cholesterol lowering, the RR in total cholesterol of less than $5 \%$ was 0.98 ( $95 \% \mathrm{CI}, 0.67$ to $1.45, \mathrm{P}=0.93$ ), and the RR in total cholesterol of $5 \%$ or more was $1.04(95 \%, 0.92$ to $1.18, \mathrm{P}=0.49)$. Although we found inverse relation between total cholesterol lowering and incidence of stroke, the results were not affected by subgroup analysis. Similarly, there seemed to be related between total cholesterol lowering and incidence of fatal stroke, triglyceride lowering and incidence of stroke, or fatal stroke. However, the effect of relation was not a statistically significant, and the results were not affected by subgroup analysis.

Subgroup analysis was performed for stroke, and fatal stroke. We observed that gemfibrozil therapy was associated with a statistical significant difference on the risk of stroke (RR, 0.72, 95\% CI, 0.53 to $0.98, \mathrm{P}=0.04$, Table 3). Furthermore, fibrate therapy might play a role in preventing the event of fatal stroke (RR, $0.41,95 \% \mathrm{CI}, 0.17$ to $1.00, \mathrm{P}=0.049$, Table 3 ), when we included the trials with Jadad score of 4. However, no other significant differences were identified between the effect of fibrate therapy and placebo based on other subset factors.

Egger's test [16] was used to check potential publication bias. There was no evidence of publication bias for the outcomes of fatal stroke (P value for Egger's test, 0.34). However, we observed the evidence of publication bias for stroke (P value for Egger's test, 0.034). Subsequently, we used trim and fill methods [26] and found that the conclusion was not changed after adjusting the publication bias.

\section{Discussion and conclusion}

The results of our study indicated that fibrate therapy has no effect on the incidence of stroke, and fatal stroke.
Although VA-HIT study [10] has shown that fibrate therapy can significantly reduce the risk of stroke, this significant effect became attenuated or balanced by pooling analysis with other trials.

The inverse relation between the total cholesterol lowering and incidence of stroke indicated that there is causal relationship beween total cholesterol and the risk of stroke. Previous meta-analysis [5] indicated that statins could effectively achieve target cholesterol goals and reduce the risk of the event of stroke, which demonstrated the relation between total cholesterol and the incidence of stroke. Two previous large randomized controlled trials, VA-HIT study [10] and BIP study [8], suggest different conclusions. The VA-HIT study [10] indicated that gemfibrozil therapy significantly reduced the risk of stroke, which was consistent with our study. However, BIP study [8] suggest that although bezafibrate therapy increased the high density lipoprotein (HDL) level and decreased triglyceride level, no effect was observed on the incidence of stroke. Therefore, we carried out a comprehensive systematic review and metaanalysis to explain the possible effect of fibrate therapy on the event of stroke. Our study was based on randomized controlled trials and explored any possible correlation between fibrates therapy and the outcomes of stroke-related disease.

Our main findings are compared with the findings of previous individual randomized controlled trials and support the conclusion made by all included individual trials except for VA-HIT study [10]. No significant difference in the relative risk of stroke, or fatal stroke was reported across a wide background of high-risk participants. In our study, participants with a history of stoke, diabetes mellitus, myocardial infarction, coronary disease, lower extremity arterial disease, or high levels of 
cholesterol, were included. However, an unimportant heterogeneity was detected on the risk of stroke or fatal stroke for the included trials. Another important factor that may affect the results is the degree of total cholesterol lowering, although stratified analysis based on the changing of total cholesterol suggested it had no effect on the risk of stroke. However, subgroup analysis indicated that the RR of fibrate therapy on the risk of stroke ranged from 0.93 to 1.15 , and fatal stroke ranged from 0.69 to 0.81 when based on baseline total cholesterol level. The reason for the suboptimal effect of fibrate therapy could be that fewer trials reported the data of stroke or fatal stroke events. Furthermore, although the information about degree of total cholesterol lowering was available, few trials reported some specific index, such as the changing of LDL. As a result, we were unable to assess the relationship between the level of reduction in some specific index and the event of stroke, or fatal stroke.

The relationship between serum total cholesterol levels, LDL and stroke were described in previous individual trials [27-30]. Epidemiological studies [31-33] also indicated that low serum level of HDL had the risk of cerebrovascular event. VA-HIT study [10] also supported this conclusion. They illustrated that gemfibrozil increased serum HDL levels by $6 \%$, reduced triglyceride levels by $31 \%$, and the levels of serum LDL remained same. This study indicated that gemfibrozil therapy could effectively reduce the risk of stroke. However, in BIP study [8] bezafibrate therapy increased HDL by $18 \%$, reduced TG by $21 \%$, and LDL by $6.5 \%$, BIP study [8] concluded that fibrate therapy did not have an effect on the incidence of stroke. We noted that the LDL values were higher in BIP study [8] than in VA-HIT study [10], which might play an important role to lessen or counter the effect of fibrate therapy on the risk of stroke.

Although our study demonstrated no significant differences between fibrate therapy and placebo in respect of fatal stroke, when excluded WHO-COOP committee of principal Investigators study [20] and LEADER study $[21,22]$ (two trials specifically included individuals without previous with diabetes, cardiovascular disease or stroke), a sensitivity analysis indicated that fibrates might play a role in fatal stroke (RR, $0.49,95 \% \mathrm{CI}, 0.26$ to 0.93 , without evidence of heterogeneity of effect). The reason for this result could be that fibrate therapy resulted in improved serum lipid profiles, which contributed an important role in the reduction of the incidence of recurrent event of stroke.

In our study, subgroup analysis illustrated that gemfibrozil therapy was associated with the reduction of risk of stroke, which was decreased by $28 \%$ (RR, $0.72,95 \% \mathrm{CI}$, 0.53 to 0.98$)$. However, these conclusions might be unreliable because only a smaller number of trials $[10,21]$ were included in such subsets. We just gave a relative result by comparing gemfibrozil therapy with placebo and provided a synthetic and comprehensive review.

Our study also has several potential limitations. Firstly, the result was based on published data, while individual patient data and original data were not available, which limited the capacity to fully explore the effects in subgroup analysis. Secondly, although subgroup analysis indicated that fibrate therapy significantly reduced the risk of stroke, or fatal stroke for patients used gemfibrozil, or Jadad score of 4 , these results might be variable due to the small number of trials. Furthermore, different baseline characteristic among participants might contribute to the lack of difference revealed in our analysis.

In conclusion, our research suggested that fibrate therapy had no significant effect on stroke, or fatal stroke. Furthermore, our study could help personally appropriate judgments about their own use of fibrate therapy, and provide evidence to prevent the incidence of fatal stroke in patients with cardiovascular disease or previous stroke. Therefore, in future study, it is important to focus on patients with previous stroke or cardiovascular disease for secondary prevention of the event of stroke or recurrent stroke, and to combine other lipid-lowering therapy, such as statins, to provide an optimal therapy to prevent the incidence of stroke. We suggest that the future trials could be improved by the following ways: (i) promising interventions should be tested, including dosage, duration of treatment or combination with influencing factors, through which we might confirm the optimal time of treatment, the optimal dosage and the optimal therapy. (ii) adverse event of trials should be reported in details so that the side-effects of any treatment could be evaluated in future trials.

\section{Additional file}

Additional file 1: PRISMA 2009 Checklist.

Competing interests

The authors declare that they have no competing interests.

\section{Authors' contributions}

$\mathrm{YHZ}$ and $\mathrm{JH}$ participated in the conceptualization and design of the review, performed the selection of studies, data-extraction and -analysis, and drafted the review. YHZ and XFY were involved in the conceptualization and design of the review, and the data analysis. FFY and $X Z$ participated in the selection of studies and data-extraction. $\mathrm{YHZ}$ and $\lrcorner \mathrm{L}$ carried out the statistical analysis and interpretation of data. All authors participated in revising the manuscript and the final approval of the manuscript.

\section{Acknowledgement}

This study was conducted under a grant from the key discipline construction of evidence-based public health in Shanghai (12GWZX0602) and three grants from the Ministry of Science and Technology of China (2008ZX10002-018, 2008ZX09312-007,2009ZX09312-025). 
Received: 10 May 2012 Accepted: 25 December 2012

Published: 3 January 2013

\section{References}

1. Williams GR, Jiang JG, Matchar DB, Samsa GP: Incidence and occurrence of total (first-ever and recurrent) stroke. Stroke 1999, 30:2523-2528.

2. Yusuf S, Reddy S, Ounpuu S, et al: Global burden of cardiovascular diseases, I: general considerations, the epidemiologic transition, risk factors, and impact of urbanization. Circulation 2001, 104:2746-2753.

3. Frick MH, Syvanne M, Nieminen MS, et al: Prevention of the angiographic progression of coronary and vein-graft atherosclerosis by gemfibrozil after coronary bypass surgery in men with low levels of HDL cholesterol. Circulation 1997, 96:2137-2143.

4. Syvanne M, Nieminen MS, Frick MH, et al: Associations between lipoproteins and the progression of coronary and vein-graft atherosclerosis in a controlled trial with Gemfibrozil in men with low baseline levels of HDL cholesterol. Circulation 1998, 98:1993-1999.

5. Amarenco P, Labreuche J: Lipid management in the prevention of stroke: review and updated meta-analysis of statins for stroke prevention. Lancet Neurol 2009, 8:453-463.

6. Austin MA, King M-C, Vranizan KM, Krauss RM: Atherogenic lipoprotein phenotype: a proposed genetic marker for coronary heart disease risk. Circulation 1990, 82:495-506.

7. Frick MH, Elo O, Haapa K, et al: Helsinki Heart Study: primary-prevention trial with gemfibrozil in middle-aged men with dyslipidemia. Safety of treatment, changes in risk factors, and incidence of coronary heart disease. N Engl J Med 1987, 317:1237-1245.

8. The BIP study group: Secondary prevention by raising HDL cholesterol and reducing triglycerides in patients with coronary artery disease. The bezafibrate infarction prevention (BIP) study. Circulation 2000, 102:21-27

9. Brunzell JD: Hypertriglyceridemia. N Engl J Med 2007, 357:1009-1017.

10. Rubins HB, Robins SJ, Collins D, et al: Gemfibrozil for the secondary prevention of coronary heart disease in men with low levels of highdensity lipoprotein cholesterol. N Engl J Med 1999, 341:410-418.

11. Moher D, Liberati A, Tetzlaff J, et al: Preferred Reporting Items for Systematic Reviews and Meta-Analysis: The PRISMA Statement. Plos Medicine 2009, 6: .

12. Jadad AR, Moore RA, Carroll D, et al: Assessing the quality of reports of randomized clinical trials: is blinding necessary? Control Clin Trials 1996, 17:1-12

13. DerSimonian R, Laird N: Meta-analysis in clinical trials. Control Clin Trials 1986, 7:177-188

14. Ades $A E$, Lu G, Higgins JP: The interpretation of random-effects metaanalysis in decision models. Med Decis Making 2005, 25:646-654.

15. Deeks JJ, Higgins JPT, Altman DG: Analyzing data and undertaking metaanalyses. In Cochrane Handbook for Systematic Reviews of Interventions 5.0.1. Edited by Higgins J, Green S. Oxford, UK: The Cochrane Collaboration; 2008:chap 9.

16. Egger M, Davey Smith $G$, Schneider M, Minder C: Bias in meta-analysis detected by a simple, graphical test. BMJ 1997, 315:629-634

17. Acheson J, Hutchinson EC: Controlled trial of clofibrate in cerebral ascular disease. Atherosclerosis 1972, 15:177-183.

18. The Veterans Administration Cooperative Study Group: The treatment of cerebrovascular disease with clofibrate. Final report of the veterans administration cooperative study of atherosclerosis, Neurology Section. Stroke 1973, 4:684-693.

19. The Coronary Drug Project Research Group: Clofibrate and niacin in coronary heart disease. JAMA 1975, 231:360-381.

20. W.H.O Cooperative trial committee of principal investigators: A co-operative trial in the primary prevention of ischemic heart disease using clofibrate, report from the committee of principal investigators. Br Heart J 1978, 40:1069-1118

21. Meade TW: Design and intermediate results of the Lower Extremity Arterial Disease Event Reduction (LEADER) trial of bezafibrate in men with lower extremity arterial disease. Curr Control Trials Cardiovasc Med 2001, 2:195-204

22. Meade $T$, Zuhrie $R$, Cook $C$, et al: Bezafibrate in men with lower extremity arterial disease: randomised controlled trial. BMJ 2002, 325:1139.

23. Whitney EJ, Krasuski RA, Personius BE, et al: A randomized trial of a strategy for increasing high-density lipoprotein cholesterol levels: effects on progression of coronary heart disease and clinical events. Ann Intern Med 2005, 142:95-104.

24. The FIELD study investigators: Effects of long-term fenofibrate therapy on cardiovascular events in 9795 people with type 2 diabetes mellitus (the FIELD study): randomised controlled trial. Lancet 2005, 366:1849-1861.

25. The ACCORD Study Group: Effects of combination lipid therapy in type 2 diabetes mellitus. N Engl J Med 2010, 362(17):1563-1574.

26. Duvall S, Tweedie R: A nonparametric "trim and fill" method for assessing publication bias in meta-analysis. J Am Stat Assoc 2000, 95:89-98.

27. Scandinavian Simvastatin Survival Study Group: Randomized trial of cholesterol lowering in 4444 patients with coronary heart disease: the scandinavian simvastatin survival study (4S). Lancet 1994, 344:1383-1389.

28. LIPID Study Group: Prevention of cardiovascular events and death with pravaststin in patients with coronary heart disease and a broad range of initial cholesterol levels. New Engl J Med 1998, 339:1349-1357.

29. Sacks FM, Pfeffer MA, Moye LA, et al: The effect of pravastatin on coronary events after myocardial infarction in patients with average cholesterol levels. New Engl J Med 1996, 335:1001-1009.

30. White HD, Simes RJ, Anderson NE, et al: Pravastatin therapy and the risk of stroke. New Engl J Med 2000, 343:317-326.

31. Tanne D, Yaari S, Goldbourt U: High-density lipoprotein cholesterol and risk of ischaemic stroke mortality. Stroke 1997, 28:83-87.

32. Lindenstrom E, Boysen G, Nyboe J: Influence of total cholesterol, high density lipoprotein cholesterol and triglycerides on risk of cerebrovascular disease: the Copenhagen city heart study. Br Med $J$ 1994, 309:11-15.

33. Prospective studies collaboration: Cholesterol, diastolic blood pressure and stroke: 13,000 strokes in 45,0000 people in 45 prospective cohorts. Lancet 1995, 346:1647-1653.

doi:10.1186/1471-2377-13-1

Cite this article as: Zhou et al.: Lipid management in the prevention of stroke: a meta-analysis of fibrates for stroke prevention. BMC Neurology 2013 13:1.

\section{Submit your next manuscript to BioMed Central and take full advantage of:}

- Convenient online submission

- Thorough peer review

- No space constraints or color figure charges

- Immediate publication on acceptance

- Inclusion in PubMed, CAS, Scopus and Google Scholar

- Research which is freely available for redistribution 